\title{
DEVELOPMENT OF A MULTI-AGENT COLLISION RESOLUTION SYSTEM AT THE SUPPLY OF SPARE PARTS AND COMPONENTS TO THE PRODUCTION EQUIPMENT OF INDUSTRIAL ENTERPRISES
}

\author{
Ruslan Kapitan \\ Department of Mechanics, Printing machines and technology \\ Cherkasy State Technological University \\ 460 Shevchenko blvd., Cherkasy, Ukraine, 18006 \\ kapitan_ruslan@ukr.net \\ Tymofii Veretilnyk \\ Department of Mechanics, Printing machines and technology \\ Cherkasy State Technological University \\ 460 Shevchenko blvd., Cherkasy, Ukraine, 18006 \\ Vladyslav Demyanenko \\ Department of Software Engineering \\ National aerospace university named by M. E. Zhukovs`kyi the "Kharkiv aviation institute» \\ 17 Chkalova str., Kharkiv, Ukraine, 61070 \\ dvavlad@ukr.net
}

\begin{abstract}
The approach to the creation of computer facilities for the automation of the technical maintenance of production equipment (TMPE) at industrial enterprises (IE) is outlined. Meaningful and formal statement of the problem of forming solutions for identifying and eliminating collisions that arise when delivering spare parts and components for TMPE are presented. The method of formation of coordinating decisions on maintenance with spare parts and accessories for carrying out TMPE at IE is described. The organization of intellectual support of formation of coordinating decisions by recognition of potential collision in the TMPE process is offered. This procedure involves checking the real existence of the collision and issuing a coordinating decision. In this case, the decision is formed in the event of a disagreement between the need for spare parts and components for the TMPE maintenance, with their availability in the PP warehouse. The ways of software implementation of this method in the environment of multi-agent system are considered. In particular, the description of the multi-agent system developed during the prototype research is given. The prototype is implemented using CORBA technology, in accordance with DSTU ISO/ EC 2382-15:2005. The calculation of the efficiency of the application of the developed computer tools in production is shown. To assess the quality of the system, a sliding control method based on leave-on-out cross-validation (LOOCV) is applied.
\end{abstract}

Keywords: maintenance, production equipment, industrial enterprise, spare parts and components, collisions; intelligent agents.

\section{Introduction}

Currently, the effectiveness of business processes in various areas of material production is largely determined by the failure-free operation of production equipment. This fact determines the relevance of tasks related to computer support for the supply of industrial enterprises (IE) spare parts and components for technical maintenance of production equipment (TMPE). Issues related to the use of information technologies and systems for IE automated management are devoted to a significant number of publications, for example [1-7]. The activity of modern IE takes place under very dynamic conditions, therefore, the efficiency of their operation largely depends on the overall technical state of the production equipment, minimization of failures, and also the efficiency of the processes of restoring the working condition of machines and mechanisms. The abovementioned necessitates the timely ordering of spare parts for the timely TMPE. Significant achievements in this direction have been achieved by research centers of such developers as Dassault 
Systemes (France), Siemens PLM Software (Germany), Unigraphics (USA), etc. Along with this, the specificity of IE functioning does not allow directly using the corresponding standard means of automation of TMPE processes. Therefore, there is a need for further research on methods and tools for informational support of IE management processes, in terms of ensuring the proper technical condition of production equipment, with a view to developing special applied information technology. Thus, at the present time there is a scientific and applied problem, the essence of which is increasing the efficiency of IE production by ensuring the reliability of production equipment by developing and implementing information support technology for providing spare parts and components for TMPE.

The aim of research is development of an approach to improving the efficiency of IE functioning by creating a technology for informational support of TMPE processes based on special data processing and knowledge tools. The application of this approach in the process of computerization of logistics processes will make it possible to reduce the risks of failures and downtime of production equipment.

\section{Materials and Methods}

Let's imagine formally the process of providing spare parts and components $\mathrm{G}$ of a certain piece of industrial equipment $\mathrm{S}$ to the IE with a set of objects:

$$
\mathrm{G}_{\mathrm{S}}=\left\langle\mathrm{A}_{\mathrm{S}}, \mathrm{D}_{\mathrm{S}}, \mathrm{C}_{\mathrm{D}}, \mathrm{I}_{\mathrm{A}}, \mathrm{A}^{\mathrm{D}}, \mathrm{C}^{\mathrm{D}}, \mathrm{A}^{\mathrm{I}}\right\rangle
$$

where $A_{S}=\left\{a_{r}\right\}, r \in \Omega_{S}$ - set of all routine maintenance operations for a piece of equipment $S$;

$A_{S} \subset A, A=\left\{a_{1}, a_{2}, \ldots, a_{n}\right\}, n=\overline{1, N}$ - set of all operations for the TMCE in the IE;

$\Omega_{\mathrm{S}}$ - set of maintenance operations indices for a piece of equipment $\mathrm{S}$;

$D_{S}=\left\{d_{t}\right\}, t \in \sigma_{S}-$ set of parts and accessories for a piece of equipment $S, D_{S} \subset D$;

$\mathrm{D}=\left\{\mathrm{d}_{1}, \mathrm{~d}_{2}, \ldots, \mathrm{d}_{\mathrm{m}}\right\}, \mathrm{m}=\overline{1, \mathrm{~N}_{\mathrm{D}}}-$ the nomenclature of all parts for the maintenance of production equipment in an industrial enterprise;

$\sigma_{\mathrm{S}}-$ set of parts indices in a piece of equipment $\mathrm{S}$;

$\mathrm{I}_{\mathrm{A}}$ - set of components for maintenance of a piece of equipment $\mathrm{S}$;

$\mathrm{C}_{\mathrm{S}}=\left\{\mathrm{c}_{\mathrm{x}_{c}}\right\}, \mathrm{X}_{\mathrm{C}} \in \mathrm{C}_{\mathrm{E}}-$ component suppliers from the set $\mathrm{D}_{\mathrm{S}}, \mathrm{C}_{\mathrm{S}} \subset \mathrm{C}$;

$\mathrm{C}=\left\{\mathrm{c}_{1}, \mathrm{c}_{2}, \ldots, \mathrm{c}_{\mathrm{r}}\right\}, \mathrm{r}=\overline{1, \mathrm{~N}_{\mathrm{C}}}-$ set of all suppliers of spare parts and components for production equipment at IE;

$A^{D}, C^{D}, A^{I}$ - corresponding relations on sets $D_{S}, A_{S}, C_{D}, I_{A}$.

Statement 1. For any technological operation $a_{i} \in A_{S}, i \in \Omega_{S}$ of the maintenance process of a piece of equipment $S$, there are mappings $A^{D}: D_{S} \rightarrow A_{S}, C^{D}: D_{S} \rightarrow C_{S}$, and these mappings are surjective (for example, for each element of the set $A_{S}$ there exists an element of the set $D_{S}$ or $\left.\mathrm{f}^{-1}\left(\mathrm{~A}_{\mathrm{S}}\right) \neq \varnothing\right)$.

Statement 2. The mapping $A^{I}: I_{A} \rightarrow A_{S}$, by virtue of the specifics of the maintenance processes of the production equipment, is bijective.

The proofs of statements 1 and 2 follow directly from the existing principles of the organization of TMPE at IE.

The above formal description of the TMPE process is idealized, since in real production conditions there are often factors that impede the fulfillment of all the requirements of the technological regulations.

As a result of the study, the most common collisions in the implementation of the TMPE are identified, from which a representative set was formed, covering practically all possible mismatches. In this case, all collisions (and their characteristic features) arising in the process of maintenance are proposed to be divided into two groups:

1) determined and resolvable in the automatic mode;

2) insoluble in automatic mode.

The resolution of situations classified as insoluble in the automatic mode, in each individual case, is separated (and according to the individual scenario), also significantly depends on the situation itself, and requires direct decision-making by production managers of different levels. 
Production situations, which can be attributed to the first group, can be resolved automatically, using the technology of intelligent agents. To develop the nomenclature of agents, it is necessary to acquire knowledge about the subject area "Material and technical support of the technical maintenance of production equipment", the presentation of this knowledge in the form of sets of characteristics, as well as types of coordinating decisions. Knowledge of the formation of these sets can be obtained both by analyzing existing precedents, and by acquiring the knowledge of experts. Consequently, the work of the coordinator is reduced to the selection of the required version of the coordinating decision, provided that the requirements imposed by the maintenance regulations for spare parts and components for each particular unit of production equipment are met. Based on the above considerations, it is advisable to limit the nomenclature of intelligent agents for automatic identification and resolution of collisions in the TMPE process, limited to two types - agent-recognizers and coordinating agents. The structure and functions of both types of agents are similar, only the filling of their knowledge bases is different, therefore, it becomes possible in future, with algorithmic and software implementation, to unify these decision blocks and the whole system as a collection of typical fragments that differ only in the filling of knowledge bases.

For the formation of a knowledge base, standard methods for acquiring knowledge can be used, both in existing solutions $\left(\mathrm{O}_{\mathrm{T}}\right)$, using them as a training sample, or using methods of extracting expert knowledge.

Intellectual support for the formation of coordinating solutions is in recognition of potential conflicts, verification of the real existence of a collision and issue a coordinating decision in the event of a non-coordination of the need for spare parts and components for the TMPE and their availability in the warehouse of the enterprise.

Let's denote by $\mathrm{Y}=\left\{\mathrm{y}_{1}, \mathrm{y}_{2}, \ldots, \mathrm{y}_{11}\right\}$ the set of all possible collisions in the TMPE process. Since in the automatic mode only a part of the collisions can be eliminated, the set $\mathrm{Y}$ is divided into two subsets, $\widehat{\mathrm{Y}}$ solvable and $\widetilde{\mathrm{Y}}$ - insoluble collisions. In this way $\mathrm{Y}=\widehat{\mathrm{Y}} \cup \widetilde{\mathrm{Y}}, \widehat{\mathrm{Y}} \cap \widetilde{\mathrm{Y}}=\varnothing$.

The method of forming coordinating solutions for the provision of spare parts and components for TMPE processes is the following orderly set of procedures:

a) For each of the maintenance operations $G_{S}$ of a piece of equipment $S$, highlight (using a mapping $\mathrm{K}_{\mathrm{H}}$ ) the signs of potential collisions $\mathrm{H}^{\mathrm{K}}: \mathrm{K}_{\mathrm{H}} \subseteq \mathrm{H}_{\mathrm{D}}$ and form a conflictable set of operations from the elements of the set $\mathrm{A}_{\mathrm{S}}$;

b) Determine the type of each potential collision. Form two subsets - signs of solvable $K_{H}^{*}$ and insoluble $\mathrm{K}_{\mathrm{H}}^{-}$collisions in an automatic mode. For unsolvable collisions, execute a request to the user to form possible coordinating decisions;

c) For each soluble collision from $\mathrm{K}_{\mathrm{H}}^{*}$, determine the spare parts and components required for the TM (the subset $D_{S}=f^{-1}\left(K_{H}^{*}\right)$ as the complete prototype of the signs of solvable collisions);

d) By analyzing the appropriate link in the logistics supply chain $\mathrm{C}^{\mathrm{D}}$, identify the supplier $\mathrm{C}_{\mathrm{D}}$ of each spare part (or component) involved in the collision and the corresponding resolver;

e) Establish the necessary restrictions $\mathrm{O}_{\mathrm{T}}$ for the requirements of the TM operation from the set $\mathrm{A}_{\mathrm{S}}$;

f) verify the real existence of a collision by executing a query to the appropriate resolver (determine the truth $\left.\mathrm{P}^{\mathrm{O}}\left(\mathrm{O}_{\mathrm{i}}\right)=\mathrm{P}_{\mathrm{j}}\right)$;

g) In the case of a conflict (if $\mathrm{P}^{\mathrm{O}}\left(\mathrm{O}_{\mathrm{i}}\right) \neq \mathrm{P}_{\mathrm{j}}$ ), determine the method of its resolution on the existing a priori created knowledge base for the resolution of typical collisions;

h) Form a coordinating solution (from the elements of the set $\mathrm{O}_{\mathrm{T}}$ ) for each identified conflict and record this decision in the repository of use cases.

This method will allow to identify potential conflicts on the basis of components included in the assembly and the requirements of the regulations, and in the event of such collisions, to form coordinating decisions that will eliminate the probable future mismatch and ensure the TMPE in accordance with the technological regulations.

For the software implementation of the multi-agent system, in the course of research, a protocol was developed for the interaction of agents. Based on the method described above, an automaton model of a typical fragment of the multi-agent system for making coordinating 
decisions is constructed in the implementation of the TMPE in notation of hybrid models [7] (Fig. 1).

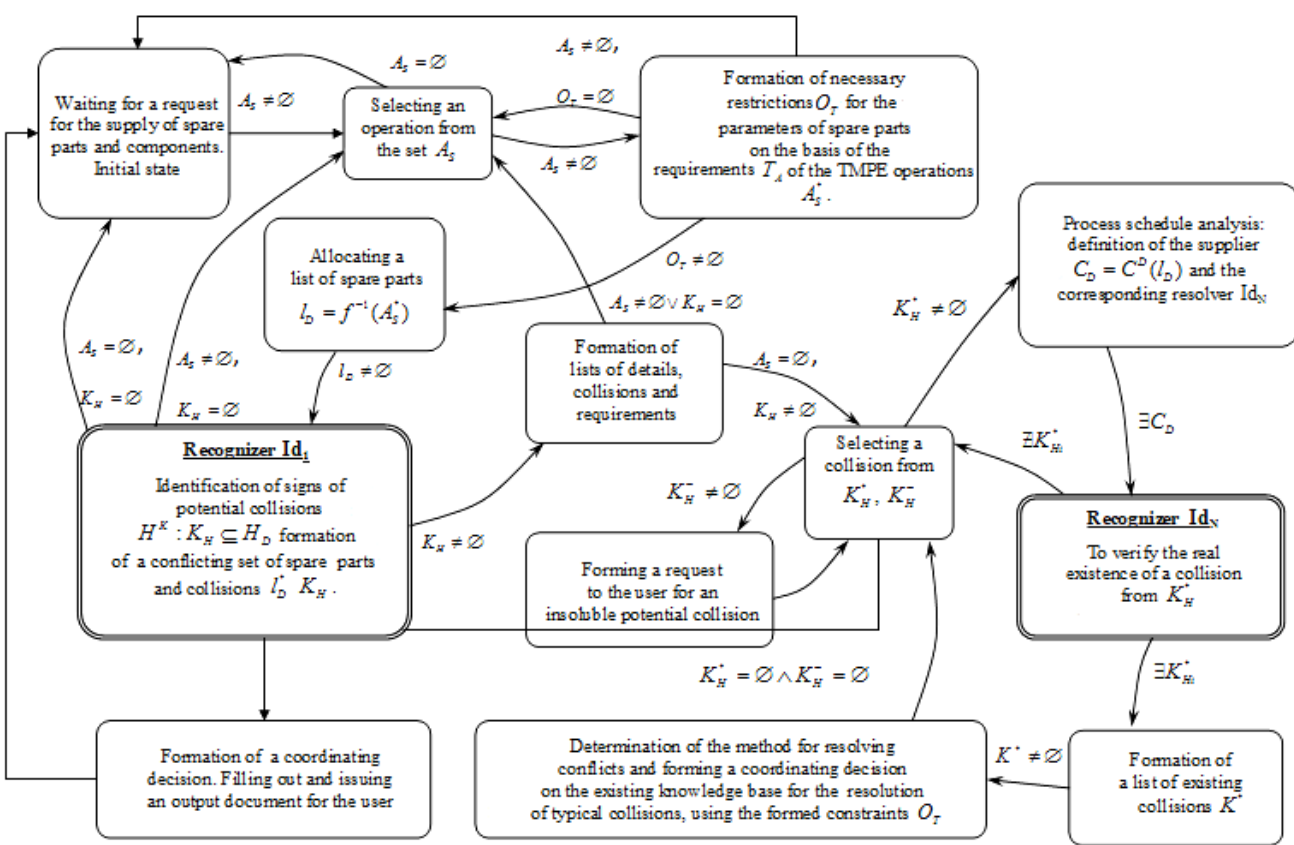

Fig. 1. Implementation of the method of forming coordinating decisions based on a hybrid approach

\section{Experimental procedures}

To illustrate the hybrid automaton approach to the synthesis of intelligent agents for the automatic formation of coordinating solutions for TMPE, a research prototype of the multi-agent system (MAS) based on the FIPA platform was developed.

Input data: current (actual at a certain point in time) values of variables defined for the domain in the form of a data exchange file; rule of reflection of variables in the form of rules (entered in the database of the rules of the agent).

Results of the agent's work: any changes in the current state of the object, obtained from the monitoring system or from other sources in the form of a change in the current values of the variables, are directly reflected in those functional elements of the MAS that are able to constantly operate with current data.

Agent operating modes:

1. Filling in the rules base and setting up the work parameters (including the connection of specific subsystems) - Fig. 2.

2. Autonomous operation in the selected mode (continuously or on request).

Fig. 2 shows the screen form of the interface part of the MAC, where:

- db_equipment.mdb, dmetal.mdb, DB.mdb - databases containing predicates of knowledge bases of the corresponding decision support subsystems (maintenance of equipment for sheet and bulk stamping and surfacing);

- change.csv - file with the current values of the object variables (obtained from the monitoring system);

- rules.mdb - knowledge base in the form of rules, which is used to update the current state of the monitoring object in the knowledge bases of the MAS subsystems.

The operation of the system is reduced to the following:

1. Reading the file with the current data from the exchange directory (having determined the presence of this file beforehand).

2. Syntactic analysis of the read file, deleting comments, possible errors, reading commands (while still under development), obtaining data about the current state (the format is coordinated with the monitoring system), recording them in the internal format of the agent. 
3. Processing of each data record of the current state consists in changing predicates of the knowledge bases of the corresponding subsystems and is performed on the basis of the rules that fill the agent's database (thus, the data is completely independent of the code and the flexibility of configuring the agent for a specific knowledge base). During the output, it is possible to reflect the change of one parameter in several knowledge bases, and also reflect changes in several parameters in one database at once. Procedure of the agent in this step:

- definition of the subsystem in which the current state is updated;

- search for the necessary database (as a structural component of the knowledge base of the corresponding subsystem);

- identification of a variable object in the database;

- performing the necessary actions on the object (update, add, delete);

- recording of each update in the general database of the current state, indicating the date and time of data receipt (forming a database of the current state with the history of changes);

- recording the results of actions in the report file (Fig. 3);

- in case of a call on the request of the program that performs monitoring, send this message to the program about the results of processing the received data.

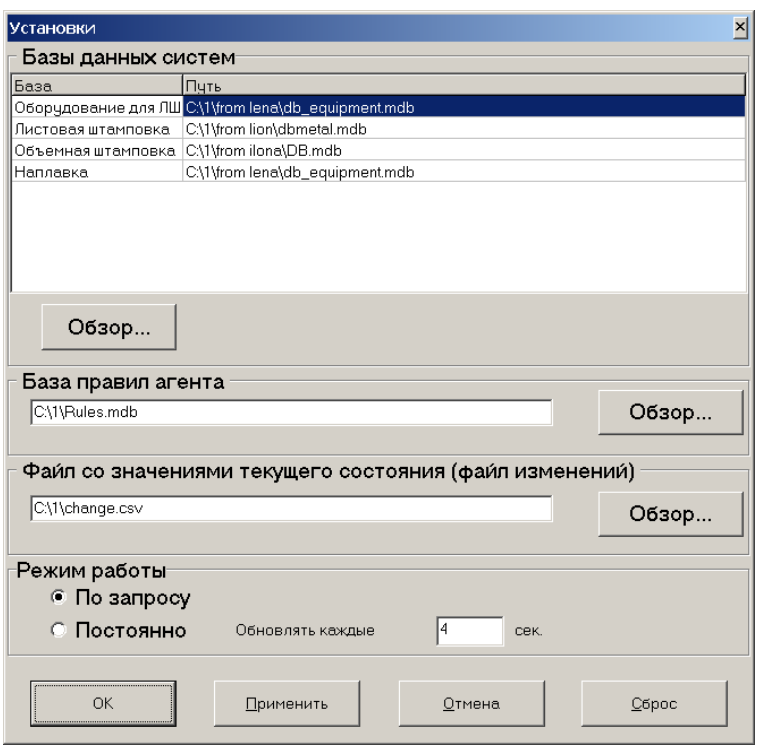

Fig. 2. Monitoring agent configuration interface - the mode of connection selection with update databases and selection of rule bases and change file

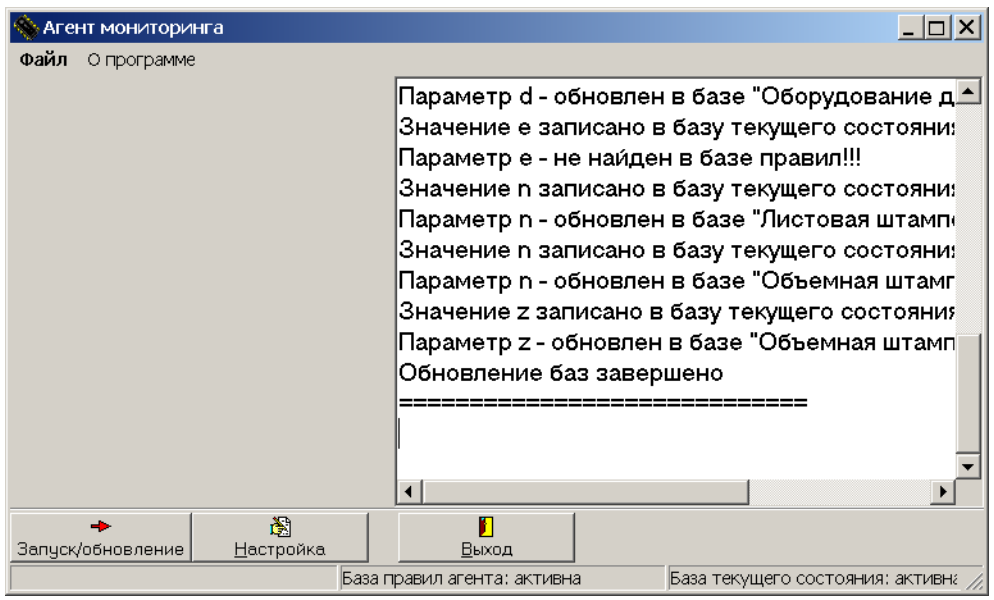

Fig. 3. Maintaining the report of the monitoring agent 
Logically, the system of reflecting the current state is a community of agents, each of which serves a certain decision-making subsystem.

For the sake of ease of administration in the prototype of the system, all agents are structured in the form of threads of one application that performs all of the above actions. There is a possibility to start simultaneously several processes that process data (with increased load per module), as well as separate the agent into several modules, to ensure the functioning of subsystems on physically different platforms.

When developing the system, a prototype was also implemented based on the CORBA technology, which is prescribed by DSTU ISO/IEC 2382-15:2005 for the construction of distributed systems.

The quality of the coordinating decisions generated by the MAS prototype was evaluated on scenario examples for training and testing the system (rules for the training and predicates for the control sample), and a comparison was made with the results of solving these situations by several experts.

Quality was determined by the general error of making the wrong decision, obtained by weighted averaging of the errors of the first kind (unrecognized situations) and the second kind (situations classified as collisions, but not so).

To assess the quality of the system, the sliding control method [8] was applied, namely, a leave-on-out cross-validation (LOOCV).

Analysis of the cost statistics for the occurrence of errors of the first and second kind (according to the training sample) shows that the costs of correcting the wrong solution for the errors of the first and second kind are $\mathrm{P}(\mathrm{y}=+1)=73 \%$ and $\mathrm{P}(\mathrm{y}=-1)=27 \%$, respectively (if we take the sum of these costs for $100 \%$ for the same situation), so losses from an unrecognized collision are much greater than losses from a "false" collision (provided that the decision to eliminate it is taken, that is, the process of TMPE will be changed in some way).

Since the errors are not equal, to estimate the total error of the system it is necessary to take the weighted values of errors of the first and second kind with weights 0.73 and 0.27 respectively.

For testing, a sample was made of 30 typical precedents that occurred in the statistics of failures of production equipment at a typical printing enterprise for 2015 [9-12]. With the involvement of experts for each case, the training rules that were used for modeling were identified, as well as the predicates that were used as the initial ones for testing at each step of the partition.

To compare the simulation results, these situations were proposed to two experts (IE technologists with at least 10 years of experience). Summary results are presented in Table 1. (the weighted error was calculated using the previously mentioned error weights of the I and II kind).

It can be seen that the rules existing in the prototype of the MAS allow to form solutions, the probability of error in which is at the level of $16 \%$, which corresponds to the value of the expert's error. It can also be concluded that the quality of the system is determined by the quality of knowledge base training, which it uses to recognize and resolve potential conflicts. Thus, by increasing the sample size, or by conducting additional sessions of extracting expert knowledge, it is possible to finish improving the quality of the system.

Table 1

The results of modeling the process of forming coordinating decisions

\begin{tabular}{|c|c|c|c|c|c|c|}
\hline & Expert 1 & Expert 2 & MAS & Expert 1, \% & Expert 2, \% & DSS, \% \\
\hline $\begin{array}{l}\text { Missed collisions } \\
\text { (error of the first kind) }\end{array}$ & 7 & 3 & 4 & $23,33 \%$ & $10,00 \%$ & $13,33 \%$ \\
\hline $\begin{array}{l}\text { Excess collisions } \\
\text { (error of the second kind) }\end{array}$ & 4 & 3 & 7 & $13,33 \%$ & $10,00 \%$ & $23,33 \%$ \\
\hline Weighted error & & & & $20,63 \%$ & $10,00 \%$ & $16,03 \%$ \\
\hline
\end{tabular}

According to the available statistics on the costs of repairing the rejection during the TMPE implementation, types of rejections were identified, which are determined by collisions recognized 
automatically in the MAS. The level of costs for repairing the marriage relative to direct material costs, as well as the ratio of the costs of repairing the rejection by species is shown in Fig. 4. Analyzing this graph, it is possible to say that the average cost of repairing the rejection by situations that are recognized by the system is about $44 \%$. Therefore, taking into account the general error in the system operation, as the probability of obtaining the wrong decision equal to 0.16 , it is possible to predict the possibility of reducing the costs associated with correcting rejects during assembly by an average of $44 \% * 0.16=37 \%$.

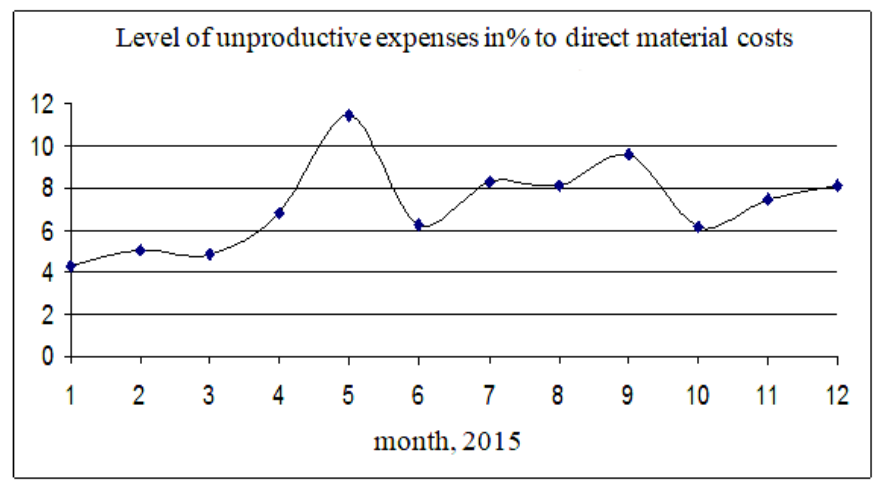

Fig. 4. Correlation of expenses for the correction of various types of rejection in the process of TMPE implementation

As a basis for the preparation of training and control samples were taken: technological regulations for the TMPE in a typical printing company; processes of maintenance of specific units of production equipment, as well as relevant statistics on costs that arose due to collisions related to the lack of spare parts and components.

\section{Discussion}

The main advantage of the presented approach is the joint application of hybrid models for the formal representation of production situations with multi-agent technology for software implementation of decision support tools.

The disadvantage of the approach is a rather narrow class of manufacturing enterprises, for which the expediency of its application is obvious a priori.

Further research should be conducted in the direction of improving the composition and functionality of the proposed multi-agent system.

The presented theoretical and applied results make it possible in the future to create a methodology for organizing information support for the subsystem of maintenance of production equipment for a wide range of industrial enterprises. The developed prototype of the multi-agent system for the formation of coordinating solutions for the provision of spare parts and components for the maintenance of production equipment can be integrated into the information management system of the ERP level.

\section{Conclusions}

The approach to the creation of computer means for the formation of coordinating solutions for the provision of spare parts and components for the maintenance of industrial equipment at industrial enterprises is considered. It is proposed to automate the process of recognizing and eliminating collisions that arise in the supply of spare parts and components, by developing a software environment that supports the life cycle of a community of intelligent agents. The nomenclature of agents is described and a hybrid model of their functioning is presented.

The efficiency of the developed means is estimated using the method of leave-on-out cross-validation. (LOOCV). As a result of the simulation, a total error level of about $16 \%$ is obtained, which will, on average, reduce the unproductive costs in the TMPE process by $37 \%$ (according to statistical data on specific types of solvable collisions). 


\section{Acknowledgments}

The authors are deeply grateful to the pro-rector for scientific work and international relations of the Cherkassy State Technological University, doctor of technical sciences, prof. V. Rudnitsky and Head of the Department of Software Engineering of the National Aerospace University "KhAI" doctor of technical sciences, prof. I. Turkin, for their support and benevolent attention during the research and during the preparation of this article for publication.

\section{References}

[1] Kutin, A. A., Turkin, M. V. (2012). Povyshenie effektivnosti funktsionirovaniia GPS v sovremennom mashinostroenii. Tehnologiia mashinostroeniia, 1, 56-59.

[2] Grigoriev, S. N., Kutin, A. A. (2011). Innovatsionnoe razvitie vysokotehnologichnyh proizvodstv na osnove integrirovannyh ASTPP. Avtomatizatsiia i sovremennye tehnologii, 11, 22-25.

[3] Dolgov, V. A. (2011). Ispolzovanie i perspektivy razvitiia CALS tehnologii v mnogonomenklaturnom proizvodstve. Avtomatizatsiia i sovremennye tehnologii, 11, 26-31.

[4] Asarin, E., Maler, O., Pnueli, A. (1995). Reachability analysis of dynamical systems having piecewise-constant derivatives. Theoretical Computer Science, 138 (1), 35-65. doi :10.1016/03043975(94)00228-b

[5] Maler, O. (2010). Amir Pnueli and the dawn of hybrid systems. Proceedings of the 13th ACM International Conference on Hybrid Systems: Computation and Control - HSCC'10, 293-295. doi: $10.1145 / 1755952.1755953$

[6] Kesten, Y., Manna, Z., Pnueli, A. (2000). Verification of clocked and hybrid systems. Acta Informatica, 36 (11), 837-912. doi: 10.1007/s002360050177

[7] Maler, O., Manna, Z., Pnueli, A. (1992). Prom timed to hybrid systems. Lecture Notes in Computer Science, 447-484. doi: 10.1007/bfb0032003

[8] Norenkov, I. P., Kuzmik, P. K. (2002). Informatsionnaia podderzhka naukoemkih izdelii. CALS-tehnologii. Moscow: MSTU n. a. N. E. Baumana, 320.

[9] Madsen, D. A. (2012). Print Reading for Engineering and Manufacturing Technology. Ed. 3. Boston, Massachusetts: CENGAGE Learning, 544.

[10] Malyshkin, E. V., Milchin, A. E., Pavlov, A. A., Shadrin, A. E. (2005). Nastol'naia kniga izdatelia. Moscow: AST; Olimp, 811.

[11] Tsentr innovatsionnoi poligrafii. Kompaniia «COLOR CITY». Available at: http://colorcity.com. ua/ru/library/articles/web2print.html. Last accessed: 2011, November 5.

[12] HP Hiflex Support. Available at: https://www.hiflex.com/hiflex/. Last accessed: 2017, October 5. 